\title{
GEOMORFOLOGIA E MORFOESTRUTURA DA CARTA JACUMÃ, ESTADO DA PARAÍBA, REGIÃO NORDESTE DO BRASIL
}

\author{
Maria Emanuella Firmino Barbosa ${ }^{1}$ \\ Wesley Ramos Nóbrega ${ }^{2}$ \\ Max Furrier ${ }^{3}$
}

\begin{abstract}
Resumo: O presente trabalho refere-se à verificação morfotectônica e morfológica, da região compreendida pela Carta Jacumã (SB-25-Y-C-III-3-NE), localizada no estado da Paraíba. As técnicas utilizadas nesta pesquisa consistiram na confecção e análise das cartas hipsométrica, de declividade, de orientação de vertentes; análise da rugosidade, perfis topográficos e modelos em 3D. Para a confecção dos produtos acima se utilizou da vetorização manual em tela da carta topográfica Jacumã, com escala de 1:25.000. Os resultados obtidos a partir das análises dos produtos gerados mostraram que no setor central da área observa-se um forte controle estrutural nos afluentes da margem direita do rio Guruji, onde os mesmos possuem um desnível altimétrico acentuado, vertentes com elevadas declividades, fortes entalhes fluviais e são mais numerosos e avantajados que os afluentes da margem esquerda. No final do curso do rio Guruji, ocorre uma forte inflexão de aproximadamente $90^{\circ}$, onde sua direção muda bruscamente de $W$ E para S-N. Outro ponto anômalo observado na área estudada foi o forte entalhamento dos afluentes da bacia do rio Graú, na porção sul da área de estudo, onde a morfologia do relevo muda de tabular para colinoso de forma abrupta e seu fluxo sofre forte inflexão no seu baixo curso mudando sua direção de W-E para NNW-SSE.
\end{abstract}

Palavras - chave: rio Guruji; rio Graú; Alto Estrutural Coqueirinho; Formação Barreiras.

\section{GEOMORPHOLOGY AND MORPHOSTRUCTURE OF THE JACUMÃ MAP, PARAÍBA STATE, NORTHEASTERN REGION OF BRAZIL}

\begin{abstract}
The present work deals with the morphostructural and morphological examination of the region encompassed by Jacumã topographic chart (SB-25-Y-C-III-3-NE), located in the State of Paraiba. The techniques used in this study consisted of the elaboration and analysis of the hypsometric, the declivity, and the slopes orientation charts; as well as the analysis of the roughness and disposition of the relief, the topographic chart of Jacumã (1:25.000), previously vectored, were used for the elaboration of the above products. The results obtained from the analysis of the products showed that in the central portion of the area there is a strong structural control on the right bank tributaries of the Guruji river, where they have a marked altimetric unevenness, high steep slopes, and deep fluvial cuts and they are more numerous and

\footnotetext{
${ }^{1}$ Doutoranda em Geodinâmica e Geofísica - Programa de Pós-graduação em Geodinâmica e Geofísica PPGG/UFRN. Aluna de Tecnologia em Geoprocessamento - IFPB. E-mail: mariaemanuellaf@gmail.com

${ }^{2}$ Aluno de Graduação em Geografia (UFPB), Departamento de Geociências. E-mail: wesjppb@gmail.com

${ }^{3}$ Professor do Programa de Pós-Graduação em Geografia UFPB/ CCEN - Campus I, Departamento de Geociências. E-mail: max.furrier@hotmail.com

DOI: 10.7154/RDG.2013.0026.0012
} 
enlarged than the left bank tributaries. At the end of the course of the river Guruji, there is a steep slant of approximately $90^{\circ}$, where its direction changes abruptly from W-E to S-N. Another anomalous point observed in the area was a large incision of the tributaries of the whatershed of Graú river, in the southern portion of the studied area, where the morphology of the relief changes abruptly from tabular to hilly and its flow is steeply slanted in its low course, changing its direction from W-E to NNW-SSE.

Key-words: Guruji river; Graú river; Coqueirinho Structural High; Barreiras Group.

\section{INTRODUÇÃO}

O presente trabalho tem como objetivo investigar, principalmente, o arranjo do padrão da rede de drenagem e o seu reflexo na morfologia do relevo, a partir da abordagem morfotectônica na região compreendida pela Folha Jacumã, com índice de nomenclatura SB-25-Y-C-III-3-NE, estado da Paraíba, nordeste do Brasil.

Essa área já possui alguns estudos referentes a movimentos tectônicos recentes (ANDRADES FILHO, 2010; BARBOSA; FURRIER, 2011), onde todos eles evidenciam o forte controle estrutural na configuração e ordenamento do relevo e no arranjo do padrão de drenagem. A utilização de técnicas de geoprocessamento para avaliação morfotectônica é fundamental, pois os produtos gerados são formidáveis para se evidenciar a morfologia do relevo onde a influência da tectônica na sua configuração e arranjo é conspícua.

O termo Neotectônica foi utilizado inicialmente por Obruchev (1948) afirmando que são movimentos da crosta terrestre ocorridos no Terciário tardio e Quaternário, com papel decisivo na formação da topografia contemporânea. E em 1978 a Comissão de Neotectônica da INQUA definiu neotectônica como qualquer movimento da terra ou deformação do nível de referência geodésico, seus mecanismos, sua origem (não importando quão antiga seja) suas implicações práticas e suas extrapolações futuras; inclui toda a escala de tempo dos movimentos, desde os instantâneos (sismos) até $10^{7}$ anos, caso necessário para permitir o entendimento da origem do movimento registrado.

O conceito de neotectonismo denota todos os tipos de movimentos crustais, verticais e horizontais (sismotectônicos, interação de placas, orogênese, subsidência de bacias, processos 
isostáticos etc.), durante um considerável período de tempo (MÖRNER, 1990). Esse período pode incluir os últimos 2,5 Ma (quando uma reorganização geral dos regimes tectônicos parece ter ocorrido), ou até os últimos 38 Ma (quando uma reorganização considerável da tectônica global parece ter ocorrido). Foi então introduzido o termo "tectônica ativa", que tem sido aplicado estritamente a eventos neotectônicos ocorridos num passado próximo, sem margem inferior fixa, que difere de lugar para lugar sendo que esse enfoque seria dado às feições e eventos que poderiam sugerir algo a respeito das atividades tectônicas num passado próximo. (MÖRNER, 1990).

Em estudos recentes, desenvolvidos a partir de 1980, vêm constatando que a influência da neotectônica sobre a configuração do relevo não pode ser mais negligenciada no Brasil, principalmente na borda oriental, devido a ajustes crustais desencadeado pelo contínuo afastamento do subcontinente sul-americano em relação ao Continente Africano (SAADI et al., 2005).

\section{Localização da Área de Estudo}

A área investigada corresponde à região compreendida pela Folha Jacumã (SB-25-Y-C-III-3-NE). A região possui uma área emersa de aproximadamente $119 \mathrm{~km}^{2}$ e está localizada no estado da Paraíba, região nordeste do Brasil, entre as coordenadas $34^{\circ} 52^{\prime} 30^{\prime \prime} \mathrm{W}, 7^{\circ} 15^{\prime} 00^{\prime \prime} \mathrm{S}$ e $34^{\circ} 45^{\prime} 00^{\prime \prime} \mathrm{W}$, $7^{\circ} 22^{\prime} 30^{\prime \prime} \mathrm{S}$ (Figura 1). 


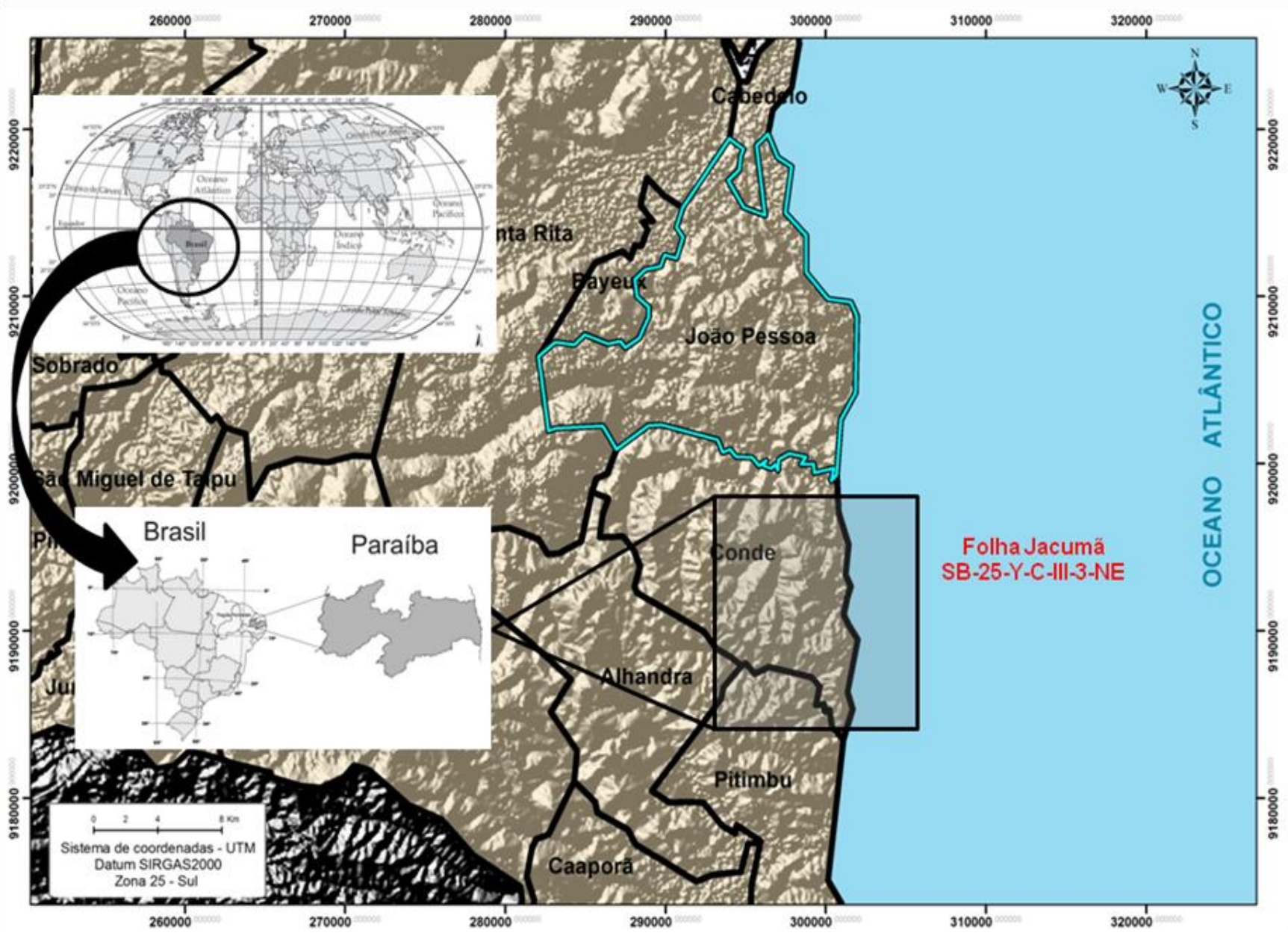

Figura 1 - Localização da área de estudo.

\section{MÉTODOS E TÉCNICAS}

O material cartográfico produzido nesse trabalho foi confeccionado com auxílio do software Spring 5.1.7. Todo o material construído foi gerado a partir da carta topográfica Jacumã vetorizada manualmente em tela, com equidistância das curvas de nível de $10 \mathrm{~m}$. O sistema de coordenadas utilizado foi o Universal Transverse Mercator (UTM) e o Datum Sistema de Referência Geocêntrico para as Américas (SIRGAS2000).

Análises morfométricas e modelos numéricos do terreno são modelagens matemáticas computacionais do relevo que apresentam grande aplicação em estudos morfotectônicos, e 
podem ser obtidas a partir do processamento de cartas topográficas, fotografias aéreas ou, mais recentemente, dados do radar SRTM (HARTWIG; RICCOMINI, 2010).

$\mathrm{Na}$ literatura, existem diversas técnicas de análise morfotectônica para esse tipo de trabalho. $\mathrm{Na}$ presente pesquisa convencionou-se utilizar a metodologia empregada por Mendes et al. (2007) e Hartwig e Riccomini (2010), que consiste na confecção e análise dos seguintes materiais: cartas referentes à hipsometria, declividade, orientação de vertentes, rugosidade do relevo, perfis topográficos e do modelo em 3D da área.

As cartas clinográfica e hipsométrica fornecem informações do gradiente altimétrico do terreno e do grau de declividade, servindo de base para identificação de vertentes, encostas e áreas alagáveis (CARVALHO; LATRUBESSE, 2004), e mais recentemente vêm sendo utilizadas como mais uma ferramenta na aferição do controle neotectônico e estrutural de uma área.

O primeiro produto cartográfico confeccionado foi a carta clinográfica, ou de declividade. Essa carta é produzida a partir das distâncias no plano horizontal e os desníveis topográficos expressos pelas curvas de nível e pontos cotados.

Um ponto importante para a confecção da carta clinográfica foi a escolha das classes de declividade, que para o presente trabalho foram utilizadas as estabelecidas por Herz e De Biasi (1989) que atrelaram essas classes a limites utilizados internacionalmente, bem como a trabalhos desenvolvidos por institutos de pesquisas nacionais e leis vigentes no Brasil.

Para confecção da carta clinográfica foi gerada a Grade Triangular Irregular, Triangular Irregular Network (TIN), que conserva a quantidade dos dados, favorecendo uma análise mais quantitativa (CÂMARA et al. 2001). Os vértices do triângulo são geralmente os pontos amostrados da superfície. Essa modelagem, considerando as arestas dos triângulos, permite que as informações morfológicas importantes como as descontinuidades, representadas por feições lineares de relevo (cristas) e drenagem (vales), sejam consideradas durante a geração de uma grade triangular, possibilitando assim modelar a superfície do terreno preservando as feições geomórficas da superfície (LOPES et al. 2006).

Na geração do TIN, o modo de triangulação utilizado nesse trabalho foi o Delaunay, que favorece a criação de triângulos o mais próximo de equiláteros possível. A tolerância de isolinhas escolhida foi de 10 metros, distância entre pontos e isolinhas de 200 metros, a 
tolerância de linhas de quebra de 10 metros e triangulação da menor aresta de 2 metros. Esses valores numéricos foram adotados pelo fato das curvas de nível preexistentes possuírem equidistância de 10 m, expondo um ótimo nível de precisão, além das dimensões reduzidas da bacia, sendo assim necessários valores baixos para a obtenção de uma triangulação com fidelidade desejável para a representação da realidade.

A carta hipsométrica consiste na hierarquização do relevo segundo a determinação de classes altimétricas representadas por cores pré-estabelecidas.

Para a confecção da carta hipsométrica da área de estudo foi necessário a vetorização das curvas de nível da carta topográfica Jacumã. Optou-se por vetorizar manualmente em tela para obter um maior detalhamento do produto final, ao invés de gerar as curvas e a rede hidrográfica de forma automática, pois o que se almeja são dados o mais fidedignos possíveis. O arquivo vetorizado foi transferido para o software Spring 5.1.7, onde foi gerada uma grade retangular em formato raster (matricial) e outro numérico. O interpolador utilizado na confecção da grade foi o Média Ponderada por Cota e Quadrante, com resolução espacial de 5 pixels. No presente trabalho foram adotados intervalos de $10 \mathrm{~m}$ até o limite de $20 \mathrm{~m}$ de altitude para delimitar de forma mais precisa áreas agradacionais e pequenas feições residuais de relevo e a partir de $20 \mathrm{~m}$ de altitude intervalos de $20 \mathrm{~m}$ até o limite de $140 \mathrm{~m}$.

A carta de orientação de vertentes mostra o rumo azimutal da reta de maior declive para uma malha de dados. Foi gerada a partir da grade triangular (TIN) onde foi efetuado o fatiamento em oito classes azimutais de $45^{\circ}$ cada uma, totalizando $360^{\circ}$.

A carta de rugosidade do relevo pode ser utilizada para estimar a correlação entre a morfologia do relevo e eventos deformacionais recentes (HOBSON, 1972). Para esse trabalho a análise da rugosidade se deu através da confecção da imagem sombreada com azimute de $180^{\circ}$ e elevação de $45^{\circ}$, para que fosse melhor evidenciado a distinção entre formas tabulares e formas colinosas do terreno. O único problema desse método é que não se pode quantificar o grau de rugosidade da área, porém para a realização da morfotectônica o mais importante é a separação desses compartimentos morfológicos, podendo a quantificação ser verificada através de outras técnicas mais pertinentes como a carta clinográfica por exemplo. 


\section{Contexto Geológico e Geomorfológico}

A área de estudo está inserida, em quase sua totalidade, sobre os sedimentos areno-argilosos mal consolidados do Formação Barreiras, uma cobertura residual de plataforma capeadora de várias bacias marginais brasileiras, entre elas, a Bacia Pernambuco-Paraíba, que abrange toda área de estudo e é constituída pelas formações Maria Farinha, Gramame e Beberibe, sendo as duas primeiras formações carbonáticas, e a última, clástica.

Na área de estudo, a Bacia Pernambuco- Paraíba encontra-se sotoposta a Formação Barreiras. Segundo Alheiros et al. (1988), essa unidade litoestatigráfica é caracterizada pela presença de fácies típicas de um sistema fluvial entrelaçado e transicionais para leques aluviais composta por depósitos de granulometria variada, apresentando cascalhos, areias grossas e finas, de coloração creme amarelada, com intercalação de microclastos de argila/silte.

Os sedimentos do Formação Barreiras provêm basicamente dos produtos resultantes da ação do intemperismo sobre o embasamento cristalino arqueado, localizado mais para o interior do continente. No estado da Paraíba, esse embasamento arqueado é composto pelas rochas cristalinas do Planalto da Borborema.

Sobre a Formação Barreiras, são desenvolvidos baixos tabuleiros com topos aplainados, ora soerguidos, ora rebaixados ou basculados por evidente atuação da tectônica recente (FURRIER et al, 2006; FURRIER, 2007). As cabeceiras de drenagem de vários cursos da região e entorno apresentam-se com elevadas declividades, estando os cursos d'água bastante encaixados e suas cabeceiras de drenagem apresentando acelerado recuo.

A Formação Maria Farinha aflora numa pequena área no baixo curso do rio Guruji, nas proximidades da linha de costa formando uma elevação proeminente e que se destaca na paisagem. Essa formação representa a continuação da sequência calcária da Formação Gramame, sendo diferenciada apenas por seu conteúdo fossilífero, que é considerada de idade paleocênica-eocênica inferior (MABESOONE, 1994). Foi erodida em parte pela exposição subaérea anterior à deposição dos sedimentos continentais da Formação Barreiras (LEAL; SÁ, 1998). 
Encontram-se nessa área diferenças altimétricas consideráveis, apontando para um sistema de blocos soerguidos, rebaixados e basculados, tendo como destaque na paisagem o Alto Estrutural Coqueirinho (FURRIER et al., 2006) de direção predominantemente W-E, que se estende desde as margens da BR 101 (já fora dos limites da área de estudo) até a retaguarda das falésias da praia de Coqueirinho, que se configuram como as falésias mais altas de todo o litoral paraibano.

\section{Análise Morfotectônica}

Analisando a carta hipsométrica (Figura 2), pode-se avaliar vários parâmetros e dimensões morfológicas distintas, dentre eles a porcentagem de área que cada categoria altimétrica abrange. $O$ resultado obtido foi que a classe altimétrica que varia entre $60-80 \mathrm{~m}$ obteve o maior valor areal, aproximadamente $29,66 \mathrm{~km}^{2}$, e o menor valor, com menos de $1 \%$ de área, com $0,028 \mathrm{~km}^{2}$, é a classe altimétrica que varia entre 100 - 120 metros de altitude. Porém, na área de abrangência do Alto Estrutural Coqueirinho, vários patamares com altitudes superiores a 120 m são encontrados fora da área de estudo, e seu ponto culminante dentro da área é de $104 \mathrm{~m}$.

Os patamares mais elevados dentro da área de estudo estão localizados ao sul do rio Graú com altitudes de até $121 \mathrm{~m}$ (ponto culminante), onde se observa também que os topos diferem-se significantemente do restante da área com morfologias e dimensões reduzidas se comparadas aos topos encontrados no compartimento ao norte do alto estrutural. Por esse setor da área possuir maiores altitudes, observa-se um maior entalhamento médio dos vales e elevadas declividades das vertentes. 


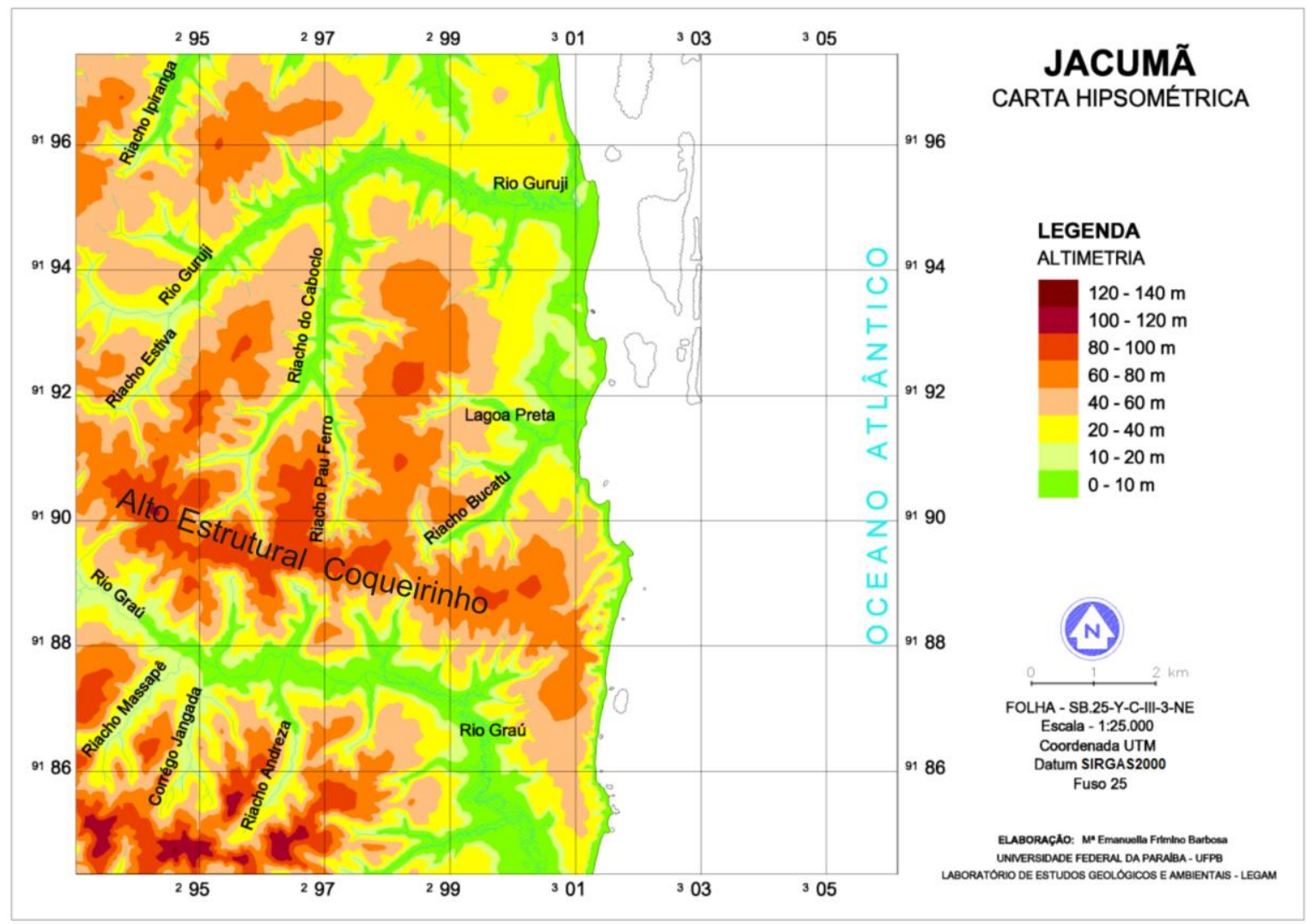

Figura 2 - Carta hipsométrica.

O segundo produto a ser analisado é a imagem sombreada do terreno (Figura 3), onde se pode observar nitidamente o forte entalhamento dos canais das duas grandes bacias localizadas na área de pesquisa (Guruji e Graú), e também o forte entalhamento do riacho Pau Ferro. Ainda sobre esse riacho, outro ponto singular é que ele possui cursos d'água que produzem acentuados entalhes, gerando vertentes com as mais elevadas declividades que serão quantificadas na análise da carta clinográfica. O riacho Pau Ferro se origina no setor central da carta onde existem patamares bastante elevados chegando a $94 \mathrm{~m}$, com topos que chegam a $104 \mathrm{~m}$.

Neste setor Sul o relevo apresenta-se bastante dissecado, com uma alta densidade da rede de drenagem, diferenciando-se praticamente de todas as outras superfícies da área de estudo. As formas predominantes são constituídas por "quase tabuleiros", às vezes, aproximando-se de formas colinosas pouco evoluídas. Esse modelado, segundo Kaizuca (1963, apud SUGUIO, 1999) 
representaria a sequência evolutiva de superfícies geomorfológicas, equivalente à fase intermediária entre as superfícies tabular e colinosa.

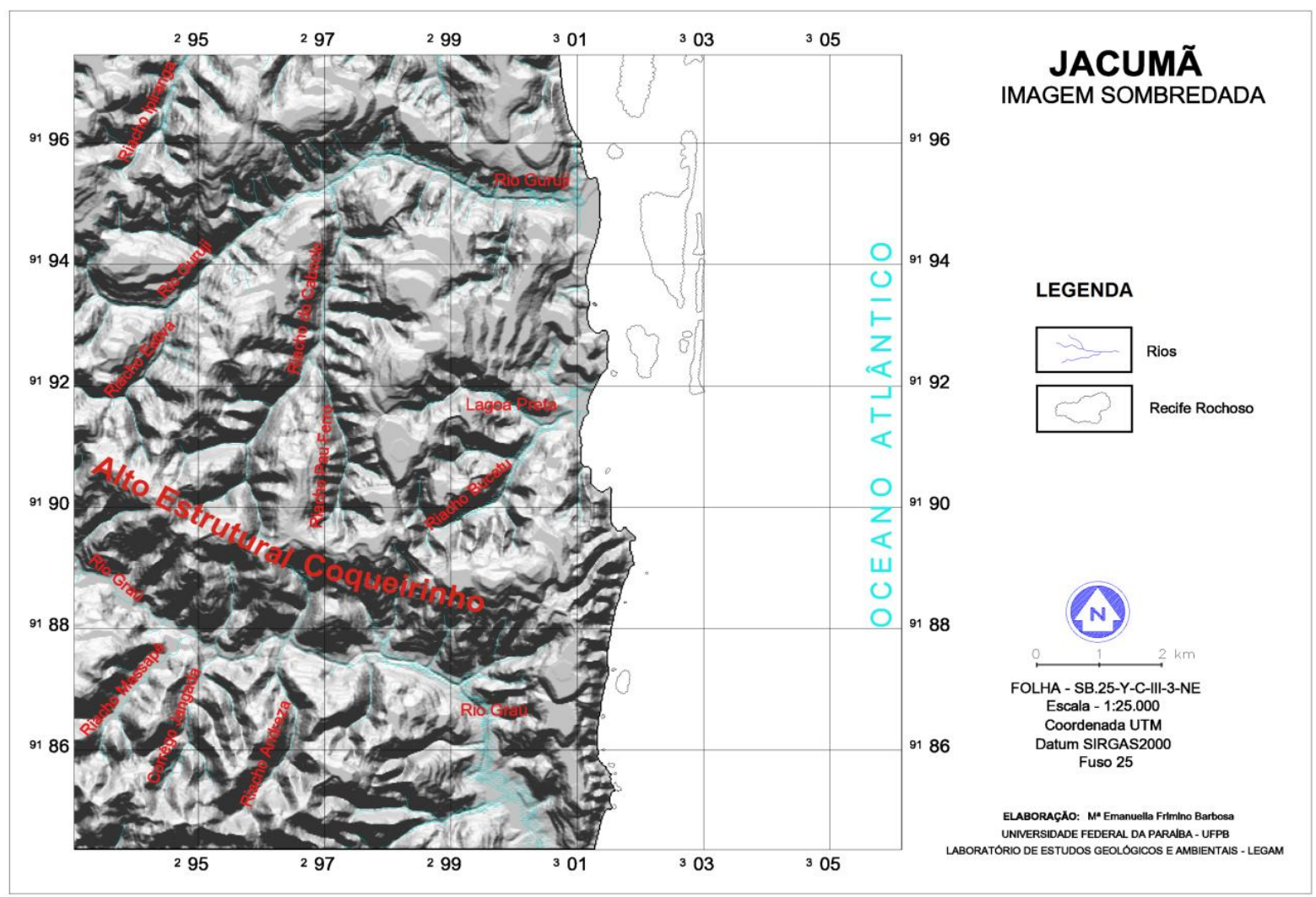

Figura 3 - Imagem sombreada, azimute $180^{\circ}$ e elevação $45^{\circ}$.

Outro elemento que pode ser avaliado e muito bem visualizado através da análise da imagem sombreada é à rugosidade do relevo. Pode-se distinguir dois grandes compartimentos bastante diferenciados separados pelo Alto Estrutural Coqueirinho, um ao norte, com formas tabulares, e outro ao sul onde a morfologia muda bruscamente passando de tabular para convexo. Nesse compartimento as altitudes são geralmente maiores e os cursos d'água entalham fortemente os canais chegando a exumar as formações sedimentares sotopostas da Bacia PernambucoParaíba, o que não ocorre no compartimento localizado ao norte do alto estrutural, onde os cursos fluviais também entalham fortemente o relevo, mas não exumam as formações sedimentares sotopostas. No setor sul da carta a rugosidade do relevo é nitidamente diferenciada, podendo ser observada visualmente sem a necessidade de cálculos 
morfométricos. A utilização de dados quantitativos como as classes de declividade, por exemplo, corrobora o que se observa na imagem sombreada.

A carta de orientação de vertentes corrobora com o que já foi estabelecido anteriormente: a divisão da área em dois compartimentos morfológicos distintos divididos pelo Alto Estrutural Coqueirinho. O compartimento localizado ao norte, onde está situada a bacia do rio Guruji, possui a maioria das vertentes voltadas, principalmente, para N - NW. O compartimento localizado ao sul do alto estrutural, onde está localizada a bacia do rio Graú é composto principalmente por vertentes voltadas para S - SW (Figura 4).

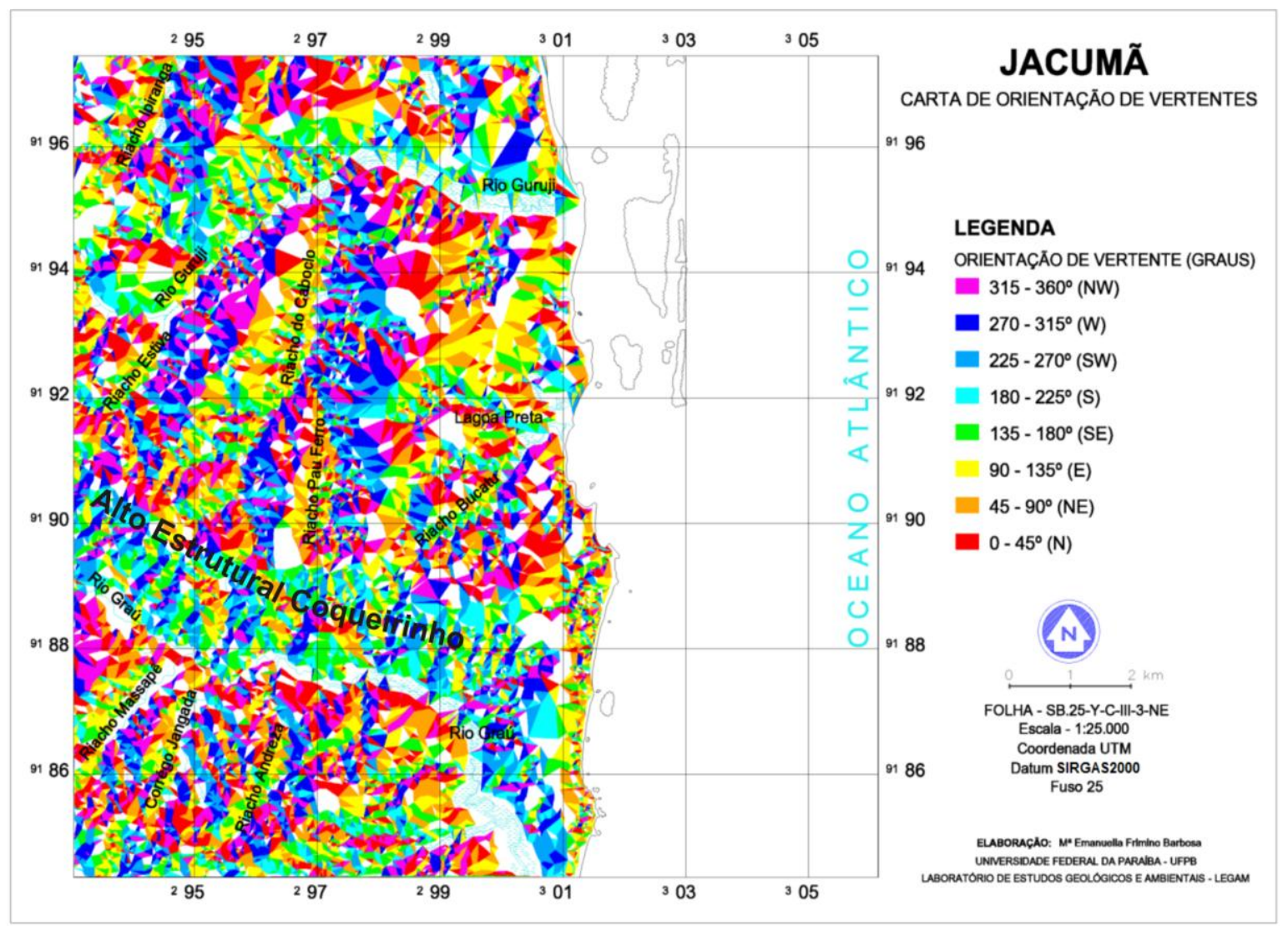

Figura 4 - Carta de Orientação de Vertente (em graus).

Na carta clinográfica (Figura 5) observa-se que as maiores declividades estão nas cabeceiras de drenagem do setor oeste e sul da bacia do rio Guruji e em praticamente toda extensão do rio Graú. Avaliando toda a área de estudo chega-se ao resultado de que uma considerável parte da 
área possui declividades em torno de 0 - 12\% que corresponde aos topos aplainados dos tabuleiros e as planícies e terraços fluviais. A maior concentração de declividades elevadas (>45\%) encontra-se ao sul do rio Graú (Figura 5).

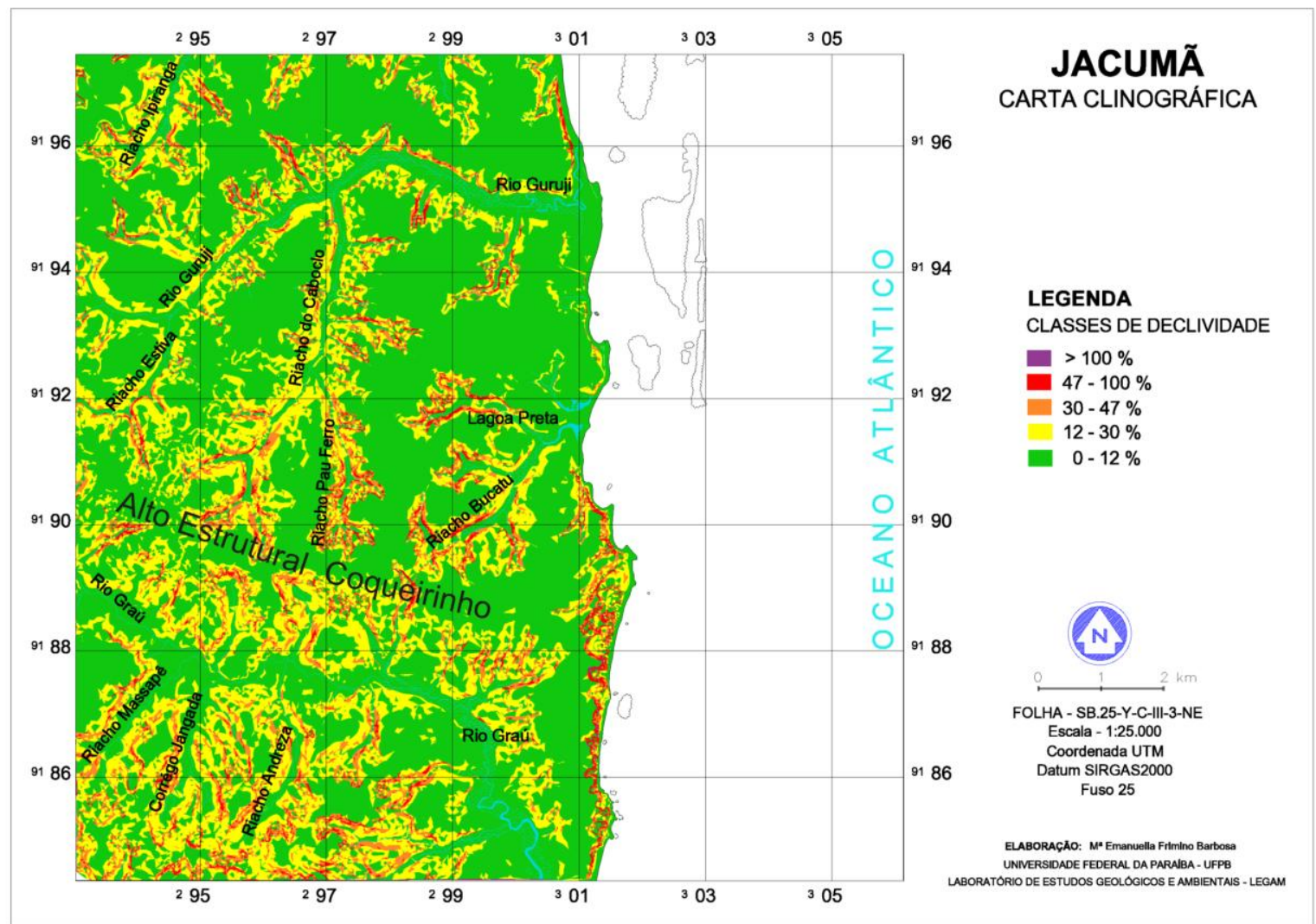

Figura 5 - Carta clinográfica.

Uma área bastante peculiar é a sub-bacia do riacho do Pau Ferro, que pertence à bacia hidrográfica do rio Guruji, onde os índices de declividade atingem valores de até $100 \%$, principalmente nas proximidades de suas cabeceiras e no seu alto curso. Em todos os seus cursos de primeira e segunda ordem percebe-se estas declividades bastante elevadas, diminuindo esse índice quando o seu curso principal deságua no riacho do Caboclo. Outra característica peculiar é sua direção S-N, destoante do padrão de drenagem principal da área que é W-E. Essas declividades elevadas apontam para um recuo de cabeceira acelerado provavelmente atrelado ao Alto Estrutural Coqueirinho, onde encontram-se todos os seus cursos de 1 a ordem. 
Com o Modelo Numérico do Terreno (Figura 6) construído e analisado, pode-se verificar com maior clareza que no compartimento norte há patamares mais elevados a oeste, declinando a altimetria em direção a leste, obedecendo à inclinação predominante das formações sedimentares da Bacia Pernambuco-Paraíba. Esse fato não pode ser aplicado para os riachos do Caboclo e Pau Ferro que apresentam direção S-N, perpendicular a direção predominante do relevo desse compartimento. Percebe-se, também, que outros cursos d'água que possuem uma pequena parte de seus caudais na área de estudo não obedecem à inclinação predominante do compartimento que é de W-E, possuindo, também direção S-N. Quanto ao compartimento ao sul do alto estrutural, visualiza-se uma acentuada inflexão do rio Graú mudando sua direção de forma brusca de W-E para NNW-SSE evidenciando neste ponto um acentuado controle tectônico-estrutural (Figura 6).

O Modelo Numérico do Terreno mostra claramente a diferença de rugosidade entre os dois compartimentos citados, além de apontar com nitidez a extensão do Alto Estrutural Coqueirinho dentro da área de estudo e sua influência conspícua nos cursos d'água que possuem direção S-N (Riachos Pau Ferro e Caboclo), destoando do padrão de drenagem regional, e na inflexão do rio Graú. 


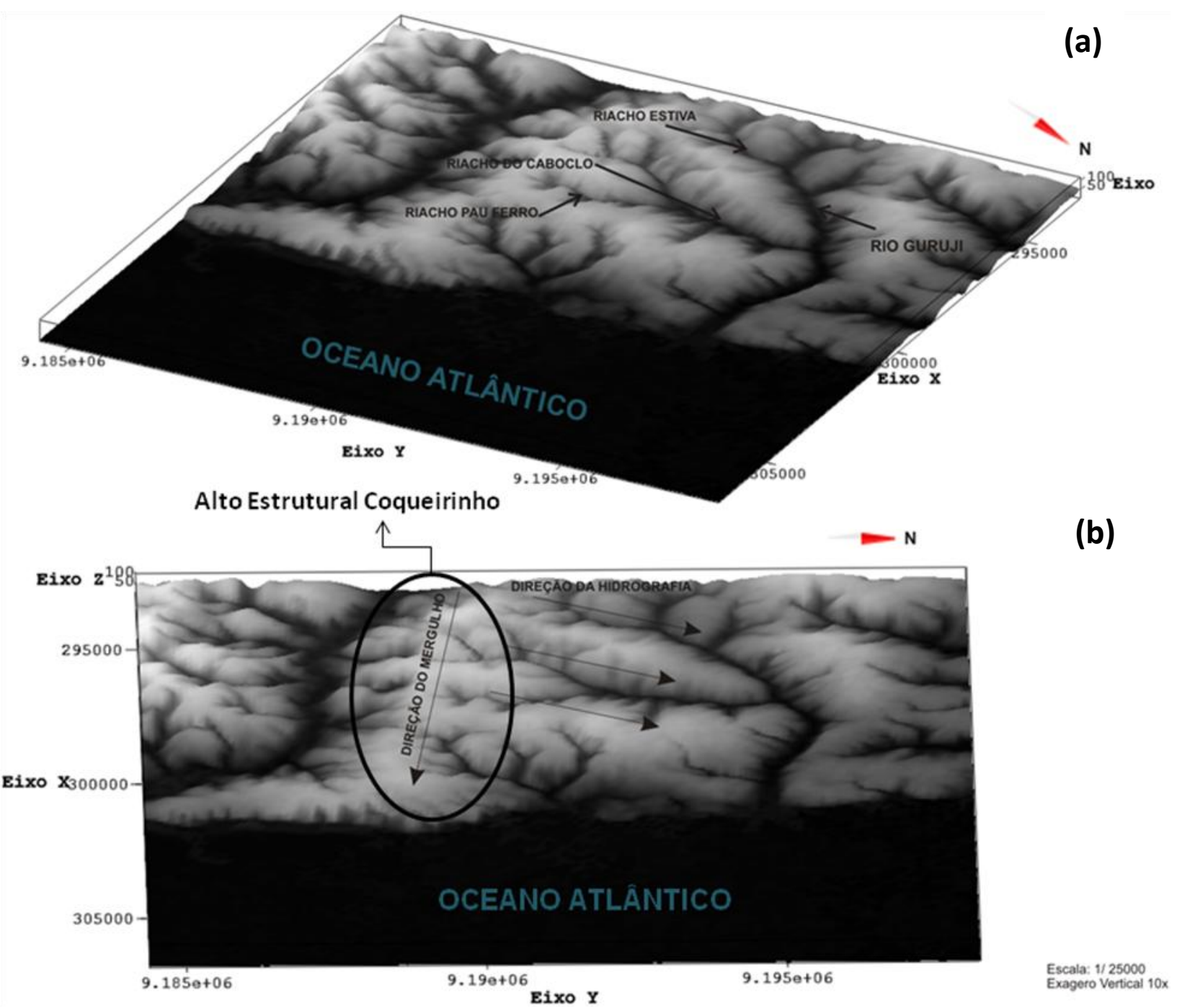

Figura 6 - Modelo Numérico do Terreno (MNT). (a) Representação do terreno mostrando a localização dos principais cursos da área de estudo. (b) Representação da inclinação das camadas sedimentares sentido E-W.

Analisando os perfis topográficos construídos automaticamente através do software SPRING 5.1.7 corrobora-se com as análises já descritas nesta pesquisa, como a divisão da área em dois compartimentos morfológicos distintos, um com relevo tabular e outro com relevo colinoso, sendo essas características visíveis no MNT (Figura 6) e Imagem sombreada (Figura 3), onde expõe dois compartimentos geomorfológicos separados por um alto estrutural e os acentuados entalhes fluviais (Figura 5).

No perfil de coordenada 293000 m pode-se observar o forte entalhe do riacho Estiva, a extensa planície do rio Guruji, no seu alto curso, algo que chama bastante atenção e uma leve inclinação 
no sentido $\mathrm{N}$ - S. No perfil de coordenada $295000 \mathrm{~m}$ pode-se contatar um basculamento no setor Leste do rio Guruji. Além disso, visualizamos nitidamente a diferenciação entre o setor norte com formas mais tabulares enquanto que na porção sul as formas encontram-se mais rugosas e com alguns vales fortemente entalhados. 

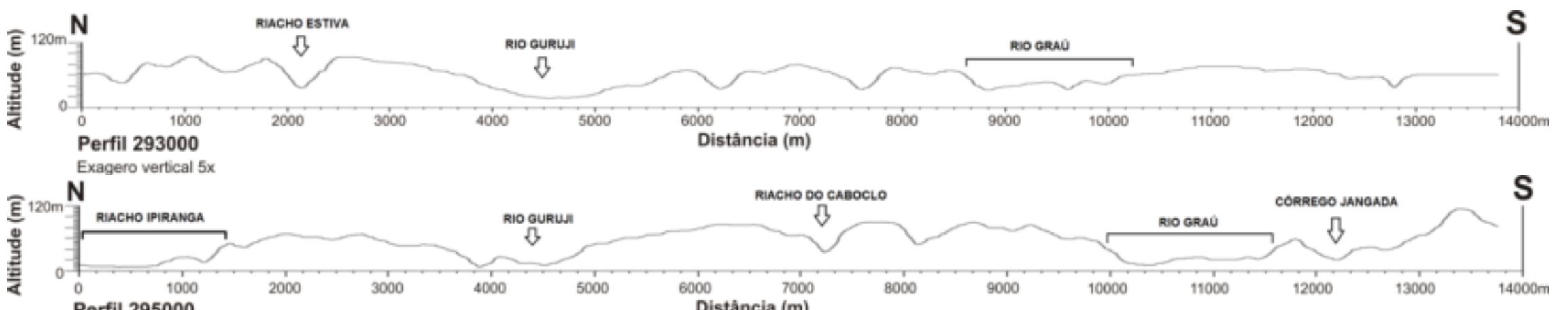

\section{Perfil 295000}

Distância $(m)$

S

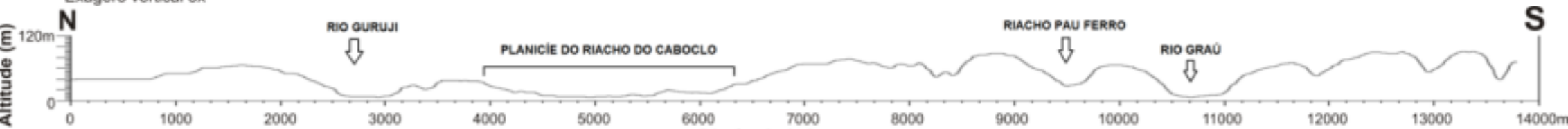

Perfil 297000

Distância $(\mathbf{m})$

11000
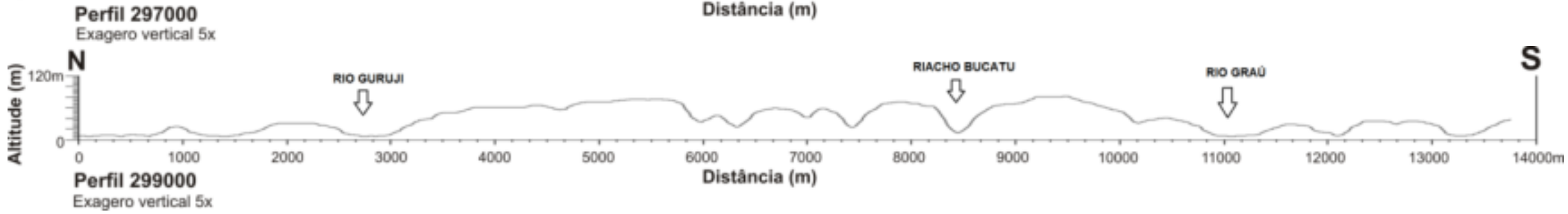

Figura 5 - Perfis topográficos das coordenadas longitudinais (sentido: N-S) da Carta Jacumã (SB-25-Y-C-III-3-NE), geradas a partir do Modelo Numérico do Terreno (MNT).

(Exagero vertical - $5 \mathrm{x}$ ) 


\section{CONSIDERAÇÕES FINAIS}

O Modelo Numérico do Terreno (MNT) gerado através do software SPRING 5.1.7 tendo como matriz a imagem das curvas de nível da carta topografia Jacumã possibilitou elaborar e confeccionar diversos produtos cartográficos que proporcionaram uma visão abrangente e precisa da área.

As cartas de declividade, hipsometria e de orientação de vertentes permitiram fazer uma descrição minuciosa da área de estudo que aponta um forte controle estrutural sobre a rede de drenagem e consequentemente sobre a configuração do relevo, sendo vista nos padrões de drenagem assimétrico, retilíneos e mudanças bruscas de direção e alguns cursos.

Os resultados das diversas análises executadas nessa pesquisa mostram uma nítida divisão do relevo em dois compartimentos distintos separados visivelmente por um alto estrutural, fortes entalhes fluviais com elevadas declividades que em alguns pontos exumam formações sotopostas da bacia sedimentar, bruscas inflexões nos dois principais rios da área (Graú e Guruji) e direções anômalas de vários cursos fluviais que possuem sentido S-N, discordantes das inclinações das camadas sedimentares sotopostas que possuem direção predominante de W-E. Essas características encontradas são evidências que o fator tectônico foi o grande influenciador na atual configuração do relevo da área e, consequentemente, dos padrões de drenagem verificados, já que a área encontra-se sob a mesma litologia, os sedimentos areno-argilosos da Formação Barreiras, e, devido sua área reduzida, não há diferenciação pluviométrica significante que poderia modelar o relevo e produzir formas e arranjos tão distintos.

O padrão de drenagem visualizado nas cartas temáticas elaboradas e confeccionadas, mostra que a hidrografia da área está intimamente atrelada ao fator estrutural e tectônico visto que seu arranjo está fortemente vinculado a um alto estrutural que corta a área, praticamente de W-E sendo o divisor de águas regional separando as duas principais bacias que desenvolveram formas de relevo e padrões de drenagem totalmente distintos.

\section{BIBLIOGRAFIA}

ANDRADES FILHO, C. O. Análise morfoestrutural da porção central da Bacia Paraíba (PB) a partir de dados MDE-SRTM e ALOS-PALSAR FBD. 2010. 150f. Dissertação (Mestrado em 
Sensoriamento Remoto) - Instituto Nacional de Pesquisas Espaciais, São José dos Campos, SP: INPE, 2010.

ALHEIROS, M. M.; LIMA FILHO, M. F.; MONTEIRO, F. A. J.; OLIVEIRA FILHO, J. S. Sistemas deposicionais na Formação Barreiras no Nordeste Oriental. In: CONGRESSO BRASILEIRO DE GEOLOGIA, 35. Anais... Belém: SBG. p.753-760. 1988.

BARBOSA, M. E. F.; FURRIER, M. Análise de bacia hidrográfica como subsídio para detecção de neotectônica: estudo da bacia hidrográfica do rio Guruji, Litoral Sul do estado da Paraíba. Cadernos de Geociências, v. 8, n. 1, p. 10-18, 2011.

CAMARA, G.; SOUZA, R. C. M.; FREITAS, U. M.; GARRIDO J. SPRING: Integrating remote sensingand GIS by object-oriented data modelling. Computers e Graphics, 20: (3) 395-403. May-Jun 1996.

CARVALHO, T. M.; LATRUBESSE, E. M. Aplicação de modelos digitais do terreno (MDT) em análises macrogeomorfológicas: o caso da bacia hidrográfica do Araguaia. Revista Brasileira de Geomorfologia. São Paulo. v.5, n.1, p. 85-93, 2004.

FURRIER, M. et.al. Geomorfologia e Tectônica da Formação Barreiras no estado da Paraíba. Geologia USP Série Científica. São Paulo, v. 6, n. 2, p. 61-70, 2006.

FURRIER, M.. Caracterização geomorfológica e do meio físico da Folha João Pessoa - 1: 100.000. 2007. 213f. Tese Doutorado. Pós-Graduação em Geografia Física, Departamento de Geografia, Universidade de São Paulo, São Paulo, 2007.

HARTWIG, M. E.; RICCOMINI, C. Análise Morfotectônica da Região da Serra dos Órgãos, sudeste do Brasil. Revista brasileira de geomorfologia. São Paulo. v. 11. n 1. p. 21 - 30. 2010.

HOBSON, R. D. Surface roughness in topography: quantitative approach In:Chorley, R.J., Spatial analysis in geomorphology, 225-245. 1972.

HERZ, F.; DE BIASE, M. Critérios e Legendas para Macrozoneamento costeiro. Brasília: Comissão Interministerial para os Recursos do Mar, 1989.

LEAL E SÁ L. T. Levantamento geológico-geomorfológico da Bacia Pernambuco-Paraíba, no trecho compreendido entre Recife-PE e João Pessoa-PB. 1998. 127f. Dissertação Mestrado. Pós- Graduação em Geociências, Centro de Tecnologia, Universidade Federal de Pernambuco, Recife, 1998.

MABESOONE J. M. Sedimentary basins of northeast Brazil. UFPE/CT/DG, Recife, 310p. 1994.

MENDES, L. D.; FERNANDES, N. F.; GONTIJO-PASCUTTI, A. H. F. Morfotectônica da bacia hidrográfica do Rio Bonito, Petrópolis-RJ. Revista brasileira de geomorfologia. São Paulo. v. 8. n 1. p. 63-77. 2007.

MORNER, N. Neotectonics and structural geology; general introduction. Bulletin International Quaternary. Association Neotectonic Commission, v. 13, p. 87, 1990. 
SAADI, A.; BEZERRA, F. H. R.; COSTA, R. D.; IGREJA, H. L. S.; FRANZINELLI, E. Neotectônica da plataforma brasileira. In: SOUZA, C. R. G; SUGUIO, K.; OLIVEIRA, A. M. S.; DE OLIVEIRA, P. E. (Eds.). Quaternário do Brasil. Ribeirão Preto: Holos,Editora, 2005. p. 211-234.

SALVADOR E. D. Análise neotectônica da região do Vale do Rio Paraíba do Sul compreendida entre Cruzeiro (SP) e Itatiaia (RJ). 1994. 124f. Dissertação de Mestrado. Pós Graduação em Geologia Sedimentar, Instituto de Geociências, Universidade de São Paulo, São Paulo, 1994.

SUGUIO, K. Geologia do Quaternário e mudanças ambientais: (passado + presente = futuro?). São Paulo: Paulo's Comunicação e Artes Gráficas, 1999. 366p.

Artigo recebido em 03/06/2013.

Artigo aceito em 26/06/2013. 